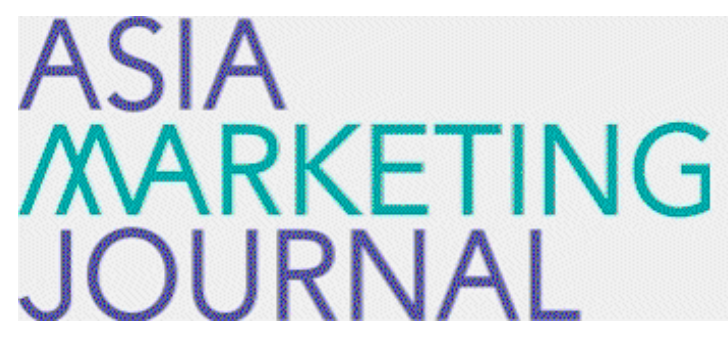

ASIA MARKETING JOURNAL

Volume 19 | Issue 4

Article 1

$1-31-2018$

\title{
The Impact of Crisis Responsibility and Risk Perception on Communication Behavior Intention in SNS
}

Eun Mi Lee

Follow this and additional works at: https://amj.kma.re.kr/journal

Part of the Marketing Commons

\section{Recommended Citation}

Lee, Eun Mi (2018) "The Impact of Crisis Responsibility and Risk Perception on Communication Behavior Intention in SNS," Asia Marketing Journal: Vol. 19 : Iss. 4 , Article 1.

Available at: https://doi.org/10.15830/amj.2018.19.4.1

This Article is brought to you for free and open access by Asia Marketing Journal. It has been accepted for inclusion in Asia Marketing Journal by an authorized editor of Asia Marketing Journal. 


\section{The Impact of Crisis Responsibility and Risk Perception on Communication Behavior Intention in SNS: Dual Processing Theory}

Social networking service(SNS) helps users manage, share and delivery a vast information as a communication tool. When users read crisis news in SNS, they communicate the information with others by considering not only their belief (i.e., cognitive risk perception) but also emotion (i.e., affective risk perception). However, few researches have been interested in the construct of communication behaviors of crisis in SNS.

This study aimed to explore the role of risk perception (cognitive and affective risk perception) between crisis responsibility and communication behavior through dual processing theory. As a result of the empirical analysis, crisis responsibility had a positive effect on cognitive risk perception and affective risk perception. In addition, cognitive risk perception had no significant effect on communication behavior whereas affective risk perception had influence on communication behavior positively. Thus, our findings may predict that the affective risk perception through crisis responsibility is more potentially important to communication behavior such as sharing information rather than cognitive risk perception. The results give insightful ideas why marketer should reduce perceived emotion caused by risk to strengthen prospective SNS users understanding of communication behavior intention.

Key words: Crisis Responsibility, Risk Perception (Cognitive Risk Perception, Affective Risk Perception), Communication Behavior Intention, Dual Processing Theory

\section{Introduction}

Recently, the number of users of social network service (SNS) has rapidly changed communication activity ecosystem. It is possible to communicate in real time through two ways communication with the message can be easily transmitted to

\footnotetext{
* Assistant Professor, Department of Business Administration and Accounting, Changshin University (emlee@cs.ac.kr)
} 
a large number of unspecified persons in one time. Successful social media contributes to the pure functional role of promoting democratization of information generating and sharing. On the other hand, it gives cooperates and marketers warning that can be both of an opportunity and a threaten. In particular, the negative news (i.e. corporate crisis) spread more fast than the positive news, and its influence is also strengthened, so cooperates are come up with counterplan against dysfunction of SNS. However, previous researches have focused on media that can be used more effectively in crisis situations, and there are few studies on communication behaviors of SNS users.

This study identifies a path model in which crisis responsibility in crisis situation affects communication behaviors of SNS users through dual processing theory. Risk perception can be driven by the interaction of the rational system and the experimental system (Epstein 1994). The rational system is based on knowledge and logic, whereas the experimental system is to encode information as the imagery based emotion. In other words, rational judgment and emotional judgment about external information or stimulation are formed through independent paths. According to the dual processing theory, the concept of risk perception suggests that cognitive risk perception and affective risk perception have an impact to communication behavior in different path processes. Based on elaboration likelihood model (ELM), cognitive risk perception refers to the process of analyzing information or stimulus of crisis that is exposed through the "central route'. It accepts the information as taking the qualitative elements significantly. Conversely, affective risk perception is formed by emotional processing as 'peripheral route'. It is an intuitive judgment of the risks associated with the context of the event related to the subject.

The prior research on crisis communication strategies insist that high and low of crisis responsibility accept highly the appropriate crisis communication strategy for each (Park and Kim 2007), or the effect of crisis communication strategies depending on crisis responsibility was not significant. The reason for this conflicting result is that those who feel anger in crisis situation demand an apology regardless of whether the corporate responsibility is high or low. In there, it is expected that the relationship between crisis responsibility and consumer attitude and behavior can be clarified if the risk perception caused by crisis responsibility is reflected in the multidimensional path (emotional or cognitive path) rather than the single dimensional path.

Thus, this study suggests the following research aims to understand risk perception with dual processing theory: First, this study explores the effect of crisis responsibility on cognitive risk perception and affective risk perception. Second, we identify the impact of cognitive risk perception and affective risk perception on communication behavior intention 
of SNS users.

\section{Theoretical Background and Hypotheses}

\subsection{Corporate Crisis and Crisis Responsibility}

Crisis leads to surprises and threats to the organization at the same time because it happens accidentally. It can also be an unexpected event accompanied by high level of uncertainty (Ulmer, Sellnow, \& Seeger 2007). Weiner (1985) argues that crisis causes negative consequences because of its nature of accelerating attribution processes. Attribution regards the motivation for explaining and understanding the phenomenon in the event of a negative and unexpected event (Weiner 1985). The reason why attribution is important in crisis management is that attribution can predict people's emotional and behavioral responses to crisis (Coombs \& Holladay 2007). One of the important factors in attribution theory is crisis responsibility. Crisis responsibility is defined to the degree to which stockholders or the public attribute responsibility of crisis event to the organization (Coombs 1995). The image of the corporate has been built upon consumers' judgement how much of it is responsible for the crisis (Coombs, 1995; 1999). The crisis is caused by the internal cause, and consumers recognize the high level of crisis responsibility for the case that the events could be controlled internally occur continuously (Coombs \& Holladay 1996). The organization needs to modify its crisis communication strategy according to the type of crisis or the extent of crisis responsibility. In this context, Coombs and Holladay (2002) suggested Situational Crisis Communication Theory (SCCT). As a result of crisis communication strategy for food crisis in SCCT, an experimental study was classified into high crisis responsibility and low crisis responsibility, and then examined acceptance of crisis communication in each case (Park and Kim 2007).

It has been studied on effects of crisis attribution and crisis communication strategies on public perception of crisis and acceptance of crisis communication have been studied (Claeys, Cauberghe \& Vyncke 2010; Hilary, Erik \& Lynn 2010; Yoon \& Choi 2008; Lee \& Lee 2006). According to Coombs and Holladay (2002), acceptance strategies are more effective for high level of crisis responsibility, and defense strategies are more effective for low crisis responsibility. However, Lee (2004) insisted that acceptance strategies have a positive impact on public perception based on sympathy. Benoit (1995) suggested that acceptance strategies are more effective than defensive strategies because public focuses on who has responsibility for crisis regardless of the cause of crisis. As such, prior researches on crisis responsibility 
and crisis communication strategies have indicted different results (Yoon \& Choi 2008; Kim \& Lee 2011).

\subsection{The Concept of Risk perception based on Dual Processing Theory}

Risk perception refers to an individual determines the severity of a specific risk. At this time, people perceive the risks to themselves or others based on past negative experiences (Weinstein 1980). Individual risk perceptions are not simply formed by objective judgment of risk severity, and involve a variety of sociocultural and psychological factors. It is important to understand the characteristics and judgment processes of individual risk perception because many decision making and behavior varies with perceived risk. Slovic and Peters (2006) have identified two dimensions - fear and knowledge - that influence risk perception. The fear refers to the degree of personal threat on risk perception such as such as fatal consequences, controllability, and threatening to the next generation. Knowledge includes personal knowledge of risk, observability, and degree of familiarity with scientific knowledge. The perceived risk is different depending on how consumers perceive these two dimensions (Kim 2012).

The dual-process theory explains that the rational system and the experimental system interact with each other to process information
(Epstein 1994). The rational system is based on knowledge and logic, and then the experimental system encodes information into an imagery based on emotion. Zajonc (1980) explained that the primary response to external stimuli is emotional. All this, emotional judgment is more efficient and faster in complex and uncertain situations as well as external stimuli and rational analysis of information are also important.

Cognitive factors consist of 'belief', 'thinking', 'information' (Ivancevich \& Matteson 1993). In other words, cognitive factors represent consumers' beliefs and knowledge concerning the object. Consumers have a lot of beliefs about specific objects, and they are attributed to brands by consumers believe in. The set of these beliefs is a cognitive component in part of attitude toward particular brands.

Thus, cognitive risk perception is formed by cognitive processing on negative information of corporate crisis events, and it conforms to 'analytical' judgment of risk. On the other hand, the affective risk perception is formed through the emotional process, and it conforms an 'intuitive' judgment. The affective risk perception is evoked immediately after encountering the risk information, while the cognitive risk perception determined through the subject's thinking process (Slovic et al. 2004).

According to Coombs and Holladay (2004) studied the stakeholder's emotion on crisis communication strategies, crisis caused by organizations' intentionality leads to extreme 
anger. Another view is that anger evoked of organization's crime have a positive relationship with crisis responsibility. The public is anger by the attribution of crisis responsibility which negatively affects the relationship between the organization and the public (Coombs \& Holladay 1996). Eventually, reputation and companyconsumer relationship may be seriously damaged as consumers perceive the company has high responsibility on crisis. It hereby allows negative rumors to spread easily. In other words, crisis responsibility not only is an important factor in formation of risk perception but also is predicted to go through emotional route as well as analytical route.

Thus, the following hypotheses are proposed:

$H_{1}$ : Crisis responsibility has an effect on risk perception positively.

$H_{1-1}$ : Crisis responsibility has an effect on cognitive risk perception positively

$H_{1-2}$ : Crisis responsibility has an effect on affective risk perception positively

\subsection{Communication Behaviors}

Information determines knowledge or belief for the stimulus of the environment (Brashers, Neidig, Haas, Dobbs, Cardillo, \& Russell 2000), which is used by individuals to remove uncertainties when making decisions about specific situation (Grunig 1982). When people who are facing the problem want to explore the information in different ways, they acquire and exchange necessary information through communication with reducing uncertainty, taking action related to issues, and making better decisions. Therefore, public communication behaviors can be seen as a preliminary stage of decision making related to issues, and belief and attitude of the issues are formed by the information and knowledge gained from this process. Communication is one way of managing uncertainty in that reactions such as preventive actions are triggered (Brashers, et al. 2000).

Communication behaviors have been studied in communications including a variety of disciplines such as psychology, consumer studies, and information science (Afifi \& Weiner 2002). In particular, it is referred to as information behavior or information seeking behavior, emphasizing the acquisition of information in interaction processes through mass media or interpersonal contact. Wilson (2000) defines information behavior including information seeking and information use as the sum of human behaviors related to information sources. He also suggested that it includes both unintentional and passive information acceptance behaviors such as TV watching as well as face-to-face communication with others. Kahlor et al. (2006) and Grunig and Hunt (1984) classified riskrelated information according to communication behaviors such as information seeking and information processing behaviors.

When an individual recognizes that there is 
a problem with a specific situation or issue, they make a motivation to solve, and then these motivation conduce various communication behaviors. The purpose of information provision is divided into two major stages: For Initial stage, necessary information is collected and acquired for problem solving. For second stage, similar recognition of need is reproduced and the right solution is encouraged (Kim \& Grunig 2011). Thus, people not only learn the necessary information personally but sometimes interact with others in various ways by voluntarily communicating their own information, experiences and opinions (Raban \& Rafaeli 2007). Interactive behaviors are an information giving behavior in the social aspects and also is classified into assertive action and passive action in the personal aspects (Kim \& Grunig 2011). Information forwarding behavior is also a planned and intended information-providing behavior that strives to inform others of matters and to promote discovering better problem-solving methods. Information owners voluntarily inform themselves based on their high awareness of the problem without the requests of others (Afifi, Morgan, Stephenson, Morse, Harrison, Reichert, \&Long 2006). Information sharing behavior, on the other hand, is a passive information-providing behavior that is an unplanned behavior that provides information in response to someone's request for expertise or opinion on related issues.

In the case of general communications, the risk perception formed socially is more influential than the risk perception based on objective criteria. Therefore, in risk research, it is necessary to focus on attitudes and perceptions of public risk based on the concept of socially reconstructed risk rather than realistic and professional information on specific risks. According to Theory of social amplification of risk which explains the phenomenon that the effect of risk reporting through mass media proliferates over society as a whole, specific risk factors are amplified by interacting with social contexts in the communication process, where the mass media is responsible for expanding or reducing risks (Lee \& Park 2006).

The purpose of this study is to investigate the effect of risk perception of corporate crisis on consumer's communication responses and behavior intention by expanding prior research on crisis communication strategies that were conducted offline. Thus, the following hypotheses are proposed:

$\mathrm{H}_{2}$ : Risk perception positively affects communication behavior intention.

$$
\begin{aligned}
H_{2-1} \text { : } & \text { Cognitive risk perception positively } \\
& \text { affects communication behavior } \\
& \text { intention. } \\
H_{2-2} \text { : } & \text { Affective risk perception positively } \\
& \text { affects communication behavior } \\
& \text { intention. }
\end{aligned}
$$

SNS are online spaces where people can 
〈Figure 1〉 Research model

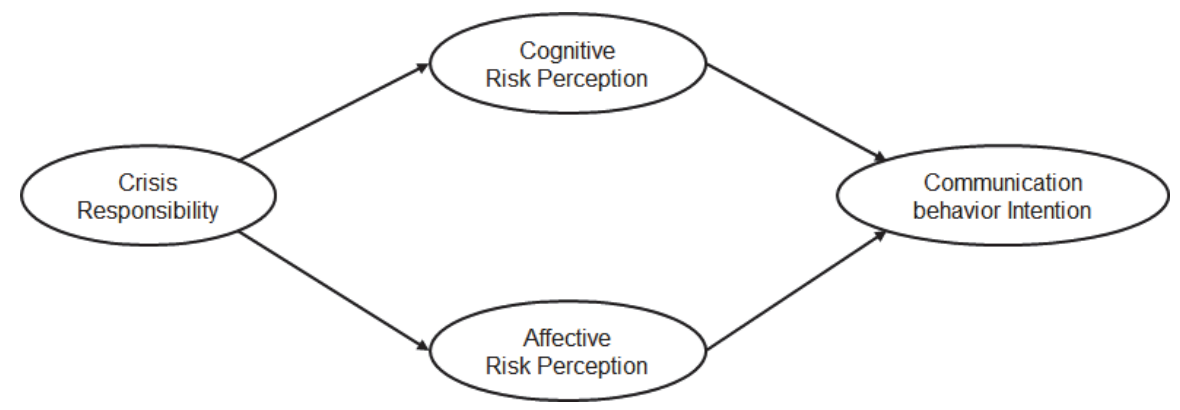

access to negative information on corporate crisis due to online distribution. According to the dual process theory, risk perception caused by crisis events is divided into two paths which are logical process (cognitive risk perception) and experiential process (affective risk perception). Based on the theoretical background, our research model was suggested in Figure 1.

\section{Research Methodology}

\subsection{Data Collection}

This study collected data through offline based survey in Busan during on November $15^{\text {th }}$ to $30^{\text {th }}$ in 2016 . Research participants are individuals who have used SNS such as Facebook, Twitter, and Blog etc. This study targeted undergraduate students because we assume that they are accustomed to use more SNS compared to other age groups.

The questionnaires were distributed to subjects of the survey along with the scenario on the drug addiction of steroid in Just-One which is a factitious pharmaceutical company for this empirical experiment. The reason for choosing drug addiction as a scenario is to recognize and recall the crisis more strongly. All subjects were asked to recall SNS what they use and imagine reading this scenario in the SNS. 105 questionnaires were coded for analysis but except for 11 questionnaires that were answered inappropriately, 94 were selected and analyzed. The gender ratio of participants was female 63 (67.2\%) and male 31 (32.8\%). The 20-29 year age group had the largest proportion at $98.3 \%$ $(n=92)$.

\subsection{Instrument development}

The measurement model was assessed using the first-order. Crisis responsibility was measured with five items applying for Coombs and Holladay's findings (2002). Risk perception was measured with the construct from perceived crisis - i.e., Stability, risk, economics, ethics, 
severity - based on Wimmer and Dominick (1994). Based on this, four items of cognitive risk perception and three items of affective risk perception were developed. Finally, two items of communication behavior intention as dependent variables were drawn from Kim and Grunig (2011).

These items for each construct were modified from the previous studies in accordance with this study and rated on a seven point Liker scale from "1" strongly disagree to "7" strongly agree.

\section{IN. Data Analysis and Results}

We used an experimental research strategy with a structural equation model using AMOS 18.0 for this study. Also, we assessed the measurement model and the structural model.

\subsection{Measurement Model}

The measurement scales and fit statistics are shown in Table 1. The convergent validity of variables was assessed based on the factor loadings, composite reliabilities (CR), and average variances extracted (AVE). As shown in Table 1, the factor loadings of all items exceeded the recommended level of 0.50 except for two items (crisis responsibility $3=$ 0.432 , crisis responsibility $4=0.362$ ). This is not to remove unsatisfied items that have less impact on our model fit. All $t$-values corresponding to the paths between the scales and their respective factors were statistically significant at a 0.001 level. The CR, which depicts the degree to which the construct indicators indicate the latent construct, exceeded the recommended level of 0.70. All these figures show that the convergent validity of variables is convincing.

A construct should share more variance within its measures than it shares with other constructs in the model (Hair, Anderson, Tatham, \& Black 1995). The average variance extracted (AVE) should exceed the square of the correlation coefficient of the construct (Fornell \& Larcker 1981). None of the squares of correlation coefficients for constructs exceeded AVE for constructs. Consequently, all constructs exhibited satisfactory discriminant validity (see Table 2).

\subsection{Structural Model}

All values meet the recommended level: $\mathrm{X}^{2}$ $=119.416$, d.f. $=65, \mathrm{GFI}=.849, \mathrm{CFI}=.924$, $\mathrm{NFI}=.852$, IFI $=.926$, RMSESA $=.095$. These statistics suggest that the data fit the model reasonably well. The results also show in Figure 2. Hypotheses $\mathrm{H}_{1-1}$ and $\mathrm{H}_{1-2}$ addresses the structural relationships among crisis responsibility, cognitive risk perception, and affective risk perception. The path between crisis responsibility and cognitive risk perception $\left(\mathrm{H}_{1-1}\right)$ was positive and significant $(\beta=0.384$, $\mathrm{t}$-value $=2.269$, 
$\langle$ Table 1〉 the results of confirmatory factor analysis for measures

\begin{tabular}{|c|c|c|c|c|c|c|}
\hline Constructs & \multicolumn{2}{|r|}{ Items } & $\begin{array}{l}\text { Stand. } \\
\text { Factor } \\
\text { loading }\end{array}$ & $\begin{array}{l}\text { Measurement } \\
\text { error }\end{array}$ & AVE & C.R. \\
\hline \multirow{5}{*}{$\begin{array}{c}\text { Crisis } \\
\text { Responsibility }\end{array}$} & 1 & $\begin{array}{l}\text { This is crisis that the company itself } \\
\text { has brought. }\end{array}$ & .838 & - & \multirow{5}{*}{0.526} & \multirow{5}{*}{0.819} \\
\hline & 2 & $\begin{array}{l}\text { It is crisis caused by the company } \\
\text { internally. }\end{array}$ & .841 & 8.159 & & \\
\hline & 3 & $\begin{array}{l}\text { It is crisis that the company could } \\
\text { control. }\end{array}$ & .432 & 4.026 & & \\
\hline & 4 & $\begin{array}{l}\text { It is crisis that has happened } \\
\text { continuously in the past. }\end{array}$ & .362 & 3.316 & & \\
\hline & 5 & $\begin{array}{l}\text { It is crisis that the company could } \\
\text { manage themselves. }\end{array}$ & .668 & 6.562 & & \\
\hline & 1 & $\begin{array}{l}\text { This case will seriously damage the } \\
\text { reputation of the company. }\end{array}$ & .833 & - & & \\
\hline Cognitive & 2 & $\begin{array}{l}\text { This case is likely to pose a serious } \\
\text { economic threat to the company. }\end{array}$ & .695 & 6.715 & 0527 & 081 \\
\hline Risk Perception & 3 & $\begin{array}{l}\text { This crisis is beyond the consumer's } \\
\text { expectation for the company. }\end{array}$ & .678 & 5.923 & 0.031 & 0.841 \\
\hline & 4 & $\begin{array}{l}\text { This crisis has a serious impact on } \\
\text { the company. }\end{array}$ & .805 & 7.698 & & \\
\hline & 1 & $\begin{array}{l}\text { The risk of this crisis leads me to } \\
\text { despise the company. }\end{array}$ & .850 & - & & \\
\hline $\begin{array}{c}\text { Affective } \\
\text { Risk Perception }\end{array}$ & 2 & $\begin{array}{l}\text { The risk of this crisis evokes the } \\
\text { wrath of me }\end{array}$ & .890 & 5.718 & 0.774 & 0.899 \\
\hline & 3 & $\begin{array}{l}\text { The risks of this crisis make me } \\
\text { angry. }\end{array}$ & .855 & 5.622 & & \\
\hline $\begin{array}{l}\text { Communication } \\
\text { Behavior } \\
\text { Intention }\end{array}$ & 1 & $\begin{array}{l}\text { I will post an article related to this } \\
\text { crisis company in the } \\
\text { I will notify the crisis company } \\
\text { through various social networks. }\end{array}$ & .684 & 2.130 & 0.624 & 0.711 \\
\hline
\end{tabular}

$\langle$ Table 2〉 the squared correlations and AVE of the constructs

\begin{tabular}{c|c|c|c|c}
\hline \multirow{2}{*}{ Construct } & \multicolumn{4}{|c}{ Correlation of constructs } \\
\cline { 2 - 5 } & 1 & 2 & 3 & 4 \\
\hline Crisis Responsibility & .526 & & & \\
\hline Cognitive Risk Perception & $.275^{* *}$ & .637 & & \\
\hline Affective Risk Perception & $.091^{* *}$ & $.138^{* *}$ & .774 & .623 \\
\hline Communication Behavior Intention & .0146 & .0026 & .0324 & \\
\hline
\end{tabular}

** $p<0.01$ / The square roots of correlation under the diagonal, AVEs are displayed on the diagonal in bold.

The Impact of Crisis Responsibility and Risk Perception on Communication Behavior Intention in SNS: Dual Processing Theory 9 
〈Figure 2〉 Results of SEM analysis

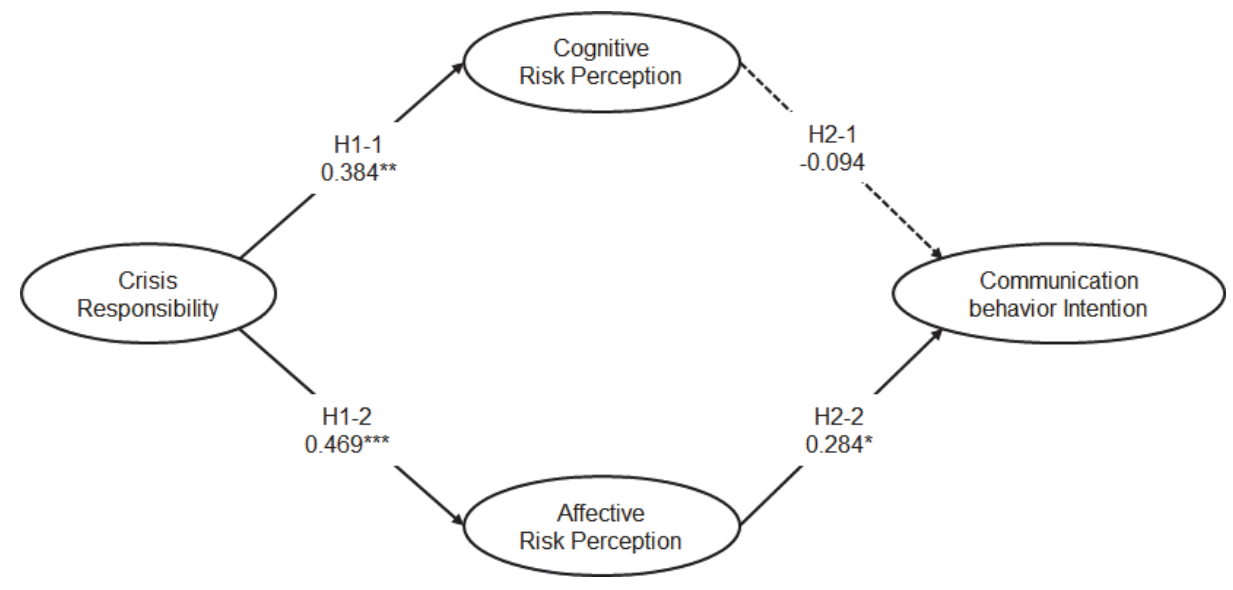

$\mathrm{p}<0.05)$. The path between crisis responsibility and affective risk perception $\left(\mathrm{H}_{1-2}\right)$ was also positive and significant $(\beta=0.469, \mathrm{t}$-value $=$ 5.019, $\mathrm{p}<0.01)$. Hypotheses $\mathrm{H}_{2-1}$ and $\mathrm{H}_{2-2}$ address the structural relationships among cognitive risk perception, and affective risk perception, and communication behavior intention. Cognitive risk perception did not have a positive effect on communication behavior intention ( $\beta=$ -0.094, $\mathrm{t}$-value $=0.406$, not supported), thus invalidating $\mathrm{H}_{2-1}$. On the other hand, $\mathrm{H}_{2-2}$ was supported by the significantly positive effect of affective risk perception on communication behavior intention $(\beta=0.284$, $\mathrm{t}$-value $=1.910$, $\mathrm{p}<0.1)$.

\section{Conclusion}

SNS are growing online places that become a public place to share a lot of information. In there, users can make the information delivery on a hair-trigger when exposing to negative information (i.e. brand rumors, scandals, and crisis). It is likely to instantly spread to the Internet and mobile. However, few researches have been interested in the construct of communication behaviors of crisis in SNS. We adopted dual processing theory and postulated the hypotheses that crisis responsibility, cognitive risk perception and affective risk perception have influence on communication behavior intention in SNS.

Our results demonstrated that crisis responsibility was a predictor of the propensity to generate the risk perception which has two paths into cognition and affect. In addition, affective risk perception was positively related to communication behavior intention. Interestingly, our findings indicated, however, cognitive risk perception do not have any significant effect on the 
communication behavior intention. This result demonstrates that people share their information on crisis event either based on emotion rather than logic in SNS.

Few studies, however, provide the reason why the effect of communication strategies did not consistent on SCCT. For instance, acceptance strategies have a positive impact on public perception based on sympathy (Lee 2004). Benoit (1995) also insisted that acceptance strategies are more effective than defensive strategies when public focuses on who has responsibility for crisis regardless of the cause of crisis. Our finding could be explained by dual process theory for these results. Crisis responsibility is an important factor for formation of risk perception by applying dual process and thus, risk perception consists of a multidimensional path rather than a single dimensional path. As a result, our findings may predict that affective risk perception for predicting communication behaviors is more potentially important, rather than cognitive risk perception.

From a theoretical perspective, this study examined empirically communication behavior intention on crisis in SNS, which seems very new trends in a online context. In addition, this study brought attention to dual path of risk perception is overachieved. Thus, our study expanded the research scope as to perspectives of dual process theory in SNS.

Our findings also bear some practical insights. The results of our study confirm that SNS users could easily exposure to the information about corporate crisis, rumors, and brand scandals by using their internet and mobile. It has also been found that perceived risk dominated negative emotion facilitates activities of communication behaviors in online as public place. Accordingly, the findings give insightful ideas why users should voluntarily share their information on crisis to strengthen prospective their understanding of psychological mechanism and to reduce user's negative affect.

Further, our empirical results showed that the role of cognitive risk perception and affective risk perception as crucial when reading articles on crisis situation. Thus, marketers or managers for managing crisis keep in mind that the SNS users in crisis situation are affected by crisis responsibility of company.

However, this study has some limitations. First, our study does not reflect individual factors such as prior knowledge, involvement, and self-efficacy with regard to contributing communication behaviors. Consequently, these factors should be tested together with our constructs in future research to explain better contribution. Second, there currently are various types of crisis information in SNS such as text-based SNS, image-based SNS, video-based SNS. Thus, the potential difference of message formats may be caused by the different types of SNS.

〈Received October 10. 2017〉

〈Accepted January 28. 2018〉 


\section{References}

Afifi, W. A., Morgan, S. E, Stephenson, M., Harrison, C. Morse, Reichert, T. T., \& Long, S. D. (2006). Examining the Decision to Talk with Family about Organ Donation: Applying the Theory of Motivated Information Management. Communication Monographs, 73, 188-215.

Benoit, W. L. (1995). Accounts, Excuses, and Apologies: A Theory of Image Restoration, Albany: State University of New York Press.

Brashers, D. E., Neidig, J. L,. Haas, S. M., Dobbs, L. K., Cardillo, L. W., \& Russell, J. A. (2000). Communication in the Management of Uncertainty: The Case of Persons Living with HIV or AIDS. Communication Monographs, 67, 63-84.

Claeys, An-Sofie, Cauberghe, V., \& Vyncke, P. (2010). Restoring Reputations in Times of Crisis: An Experimental Study of the Situational Crisis Communication Theory and the Moderating Effects of Locus of Control. Public Relations Review, 36, 256262.

Coombs, W. T. (1995). Choosing the Right Words: The Development of Guidelines for the Selection of the "Appropriate" Crisis Response Strategies. Management Communication Quarterly, 8, 447-476.

Coombs, W. T. (1999). Ongoing crisis communication
: Planning, managing, and responding. Thousand Oaks, CA: Sage Publications. Coombs, W. T. \& Holladay. S. J. (1996). Communication and Attributions in a Crisis: An Experimental Study in Crisis Communication. Journal of Public Relations Research, 8(4), 279-295.

Coombs, W. T. \& Holladay. S. J. (2002). Helping Crisis Managers Protect Reputational Assets Initial Tests of the Situational Crisis Communication Theory. Management Communication Quarterly, 16(2), 165-186. Coombs, W. T. and S. J. Holladay (2004), Reasoned Action in Crisis Communication: An Attribution Theory-based approach to Crisis Management. in D. P. Millar and R. L. Heath (Ed.), Mahwah, Responding to crisis: A Rhetorical Approach to Crisis Communication (95-115). NJ: Lawrence Erlbaum Associates.

Coombs, W. T. and S. J. Holladay (2007). The Negative Communication Dynamic: Exploring the Impact of Stakeholder Effect on Behavioral Intentions. Journal of Communication Management, 11(4), 300-312.

Epstein, S. (1994). Integration of the Cognitive and the Psychodynamics Unconscious. American Psychologist, 49, 709-724.

Fornell, C. \& Larcker, D. F. (1981). Evaluating Structural Equation Models with Unobservable Variables and Measurement Error. Journal of Marketing Research, 18(1), 39-50.

Grunig, J. E. (1982). The Message-attitude- 
behavior Relationship: Communication Behaviors of Organizations. Communication Research, 9(2), 163-200.

Grunig, J. E. \& Hunt, T. (1984). Managing Public Relations, New York: Holt, Rinehartand Winston.

Hair, J. F., Anderson, R. F., Tatham, R. L., \& Black, W. C. (1995). Multivariate Data Analysis with Reading: Prentice Hall.

Hilary, F. S., Erik, L. C., \& Lynn, M. Z. (2010). Through the Looking Glass: A Decade of Red Cross Crisis Response and Situational Crisis Communication Theory. Public Relations Review, 36, 21-27.

Ivancevich, J. M. \& Matteson, M. T. (1993). Organizational Behavior \& Management, Boston, AM: Richard D. Irwin, Inc.

Kahlor, L., Dunwoody, S., Griffin, R. J., \& Neuwirth, K. (2006). Seeking and Processing Information about Impersonal Risk. Science Communication, 28(2), 163-194.

Kim, I. S. (2012). The Impact of Risk Perception of Nuclear Power, Perception of Knowledge, the Use of Communication Channels, the Third-person Effect about Nuclear Accident on Optimistic Bias-Fukushima Nuclear Accident. Journal of Communication Science, 12(3), 79-106.

Kim, J-N. \& Grunig, J. E. (2011). Problem Solving and Communicative Action: A Situational Theory of Problem Solving. Journal of Communication, 61(1), 120-149. Kim, Yoonjin \& Kim, H-O (2011). The
Effects of Corporate Reputation and Crisis Communication on Post-crisis Corporate Reputation and Crisis Perceptions. Journal of Public Relations, 15(2), 5-39.

Lee, Betty Caman (2004). Audience-oriented Approach to Crisis Communication: A Study of Hong Kong Consumers' Evaluation of an Organizational Crisis. Communication Research, 31(5), 600-618.

Lee, S. K. and Lee, M. C. (2007). The Effectiveness of Coping Strategy for Various Types of Corporate Crises Related to Product. The Korean Journal of Advertising and Public Relations, 9(3), 186-218.

Pakr, E. H. and Kim, Y. W. (2007). The Effects of Media Framing and Image Restoration Strategies on the Public's Crisis Perceptions. Korean Journal of Communication and Information, 38(2), 73-118.

Raban, D. R. and Rafaeli, S. (2007). Investigating Ownership and the Willingness to Share Information Online. Computers in Human Behavior, 23, 2367-2382.

Slovic, Paul \& Peters, Ellen (2006). Risk Perception and Affect. Current Directions in Psychological Science, 15(6), 322-325.

Ulmer, R. R., Seeger, M. W., \& Sellnow, T. L. (2007). Post-crisis Communication and Renewal: Expanding the Parameters of Post-crisis Discourse. Public Relations Review, 33(2), 130-134.

Weiner, B. (1985). An Attributional Theory of 
Achievement Motivation and Emotion. Psychological review, 92(4), 548-573.

Weinstein, N. D. (1980). Unrealistic Optimism about Future Life Events. Journal of Personality and Social Psychology, 19, 30-53.

Wilson, T. D. (1997). Information Behaviour: An Interdisciplinary Perspective. Information Processing and Management, 33(4), 551572.
Wimmer, R. D. and Dominick, J. R. (1994). Mass Media Research: An Introduction (4th Ed.), Belmont: Wadsworth.

Yoon, Youngmin \& Choi, Y. J. (2008). Influence of Apology on Crisis Responsibility Attribution and Acceptance of Strategies. Asian communication research, 52(5), 207-226.

Zajonc, R. B. (1980). Feeling and Thinking: Preferences Need No Inferences. American Psychologist, 35, 151-175. 